\title{
Motivational activities based on previous knowledge of students
}

J. García, L. Gómez-Robledo, R. Huertas, F. Perales

J. A. García, L. Gómez-Robledo, R. Huertas, F. J. Perales, "Motivational activities based on previous knowledge of students," Proc. SPIE 9289, 12th Education and Training in Optics and Photonics Conference, 92890 S (17 July 2014); doi: 10.1117/12.2070770

SPIE Event: 12th Education and Training in Optics and Photonics Conference, 2013, Porto, Portugal 


\title{
Motivational activities based on previous knowledge of students
}

\author{
J.A. García ${ }^{1}$, L. Gómez-Robledo ${ }^{1}$, R. Huertas ${ }^{1}$, F. J. Perales ${ }^{2}$ \\ ${ }^{1}$ Departmento de Óptica. Campus Fuentenueva, Faculty of Sciences, University of Granada, E- \\ 18071 Granada, Spain. \\ ${ }^{2}$ Departamento de Didactica de las Ciencias Experimentales, University of Granada, E-18071 \\ Granada, Spain.
}

\begin{abstract}
Academic results depend strongly on the individual circumstances of students: background, motivation and aptitude. We think that academic activities conducted to increase motivation must be tuned to the special situation of the students. Main goal of this work is analyze the students in the first year of the Degree in Optics and Optometry in the University of Granada and the suitability of an activity designed for those students. Initial data were obtained from a survey inquiring about the reasons to choose this degree, their knowledge of it, and previous academic backgrounds. Results show that: 1) the group is quite heterogeneous, since students have very different background. 2) Reasons to choose the Degree in Optics and Optometry are also very different, and in many cases were selected as a second option. 3) Knowledge and motivations about the Degree are in general quite low. Trying to increase the motivation of the students we designed an academic activity in which we show different topics studied in the Degree. Results show that students that have been involved in this activity are the most motivated and most satisfied with their election of the degree.
\end{abstract}

Keywords: Motivation, Academic background.

\section{INTRODUCTION}

The step from Secondary Education to the University turns into a difficult transition from several points of view. The case of university studies in Optics does not constitute an exception. Besides, in Spain we have to add that the access to such studies is done according to different itineraries in Secondary Education and the new students don't always choose this degree as their first choice, which confers them a heterogeneous profile. In this context, those students usually also expect their curriculum to be focused almost exclusively on the denomination of their qualification, that is, Optics and Optometry, not trusting other disciplines, such as is the case in General Physics. In this context, during the first classes of Physics in this degree we habitually observe that most of our students show great difficulties to understand the subject that is explained and just a few of them find it easy; both cases result in a low motivation towards the subject, and even a certain apathy; they think they are going to learn Optics but they are finding themselves learning Mathematics and Physics.

In an attempt to reorientate the students' attitude towards Physics and their own degree studies, we set out a voluntary activity where we show them laboratory experiences represented by optical phenomena and applications. After this activity they were given a survey about different aspects related to their integration in their new studies and to their own activity. In this work, this activity is described as well as the results of the survey in order to establishing some of the factors that could improve the vocational orientation of the students and their adaptation to university studies. According to the former explanation, in the present work we have tried, in first place, to analyze the characteristics of the group that is acceding to the degree in Optics and Optometry and, in second place, to design an activity to try to improve the motivation of our students and to analyze if these types of activities achieve the goal for which they were created.

\section{INSTRUMENT}

This survey was made after a month and a half from the beginning of the course, and after having attended to one laboratory session in which we showed them different experiences about the applications of Optics. The same are shown in Table I. 


\begin{tabular}{|c|c|}
\hline Experience & Subject of Optics involved \\
\hline Invisible bar & Geometric Optics and Physical Optics I \\
\hline Polarization & Physical Optics I \\
\hline Photoelasticity & Physical Optics I and Optical Technology \\
\hline Optic Fiber & Geometric Optics and Physical Optics II \\
\hline Difraction Phenomena & Physical Optics II \\
\hline Anaglyph and holograms & Binocular Vision, Optometry, Physiological Optics and Physical Optics II \\
\hline Ametropy simulation & Physiological Optics and Optometry \\
\hline Visual Persistence & Physiological Optics \\
\hline Color blinds & Physiological Optics \\
\hline Optical Illusions & Human Vision \\
\hline
\end{tabular}

Table I. Relation of experiences shown to the students.

\subsection{Sample}

A total of 54 students completed this survey, 39 of them attended the programmed activity and 15 did not due to its voluntary character. The characteristics of the sample are shown right after (Table II).

\begin{tabular}{|c|c|c|c|c|}
\hline Sample (N) & Course of application & Degree & Age Average & Sex (\% M/F) \\
\hline 54 & $2012-13$ & Optics and Optometry & 19.4 & $\begin{array}{c}\text { M 35,2 } \\
\text { F 64,8 }\end{array}$ \\
\hline
\end{tabular}

Table II. Characteristics of the students’ sample survey respondents (M: Male; F: Female).

\section{RESULTS AND DISCUSSION}

Let's see the items and their obtained answers.

1. Why did I register in the Degree of Optics and Optometry? Indicate, from the statements below, the closest to the reasons that made you register (maximum 3 ).

This item was pretending to ask directly about the reasons why the students chose this degree. The answers are shown in Table III.

\begin{tabular}{|c|c|}
\hline Reasons & $\mathbf{N}$ \\
\hline I was told it helps to find good jobs & 37 \\
\hline I could not register in what I wanted and this was my second choice & 16 \\
\hline I assisted to orientational talks and I liked what I was told & 8 \\
\hline I was advised by my parents & 7 \\
\hline My family has an Optitons and I like this job & 6 \\
\hline I have completed the Spectacles module and I wanted to expand my studies & 4 \\
\hline I was advised in high school & 4 \\
\hline Others (mainly “I like it”) & 17 \\
\hline
\end{tabular}

Table III. Reasons why the students from sample got registered in the degree of Optics and Optometry (arranged from more to less frequency).

The most common reason has been that they got registered because it provides good job expectations. But, maybe the most surprising is that there is a large amount of students who have registered because they could not get in to the degree they truly wanted. This implies that a significant percentage of o students would prefer to study a different degree, which is why it could be very interesting for them to know the possible characteristics of this degree as soon as possible, so that they have a bit clearer their interest about it or, on the contrary, whether they decide to give up on it. 
2. Knowledge that you had about this Degree and how you find yourself doing in it. Value them depending on your level of approval or disapproval with them, from 1 (nothing) to 5 (totally).

In this item we are trying to get deeper into the students' previous reasons and the first impressions after starting their university studies. The answers (Table IV) have been separated among the students that assisted to the session of experiences -Exp. Yes- (see the next item), the one who did not assisted -Exp. No- and the total of students.

\begin{tabular}{|c|c|c|c|}
\hline Statement & Exp. Yes & Exp. No & All \\
\hline Knowledge that I had about the subjects that form it & 3.46 & 3.07 & 3.35 \\
\hline Knowledge that I had about the contents & 2.74 & 2.47 & 2.67 \\
\hline Level of motivation that I had & 4.33 & 3.73 & 4.16 \\
\hline I am more motivated to study it everyday & 4.03 & 3.27 & 3.82 \\
\hline I think I made the right choice when I registered in this Degree & 4.08 & 3.33 & 3.87 \\
\hline
\end{tabular}

Table IV. Knowledge and motivation of the students towards their new studies (Exp. Yes: Students carrying out the experience of item 3; Exp. No: Students did not).

We will comment these results on the item below.

3. Regarding the laboratory session, please value from 1 (totally disagree) to 5 (totally agree) the following statements.

The results of the item are shown in Table V.

\begin{tabular}{|c|c|}
\hline Statement & $\begin{array}{c}\text { Frequency } \\
\text { average }\end{array}$ \\
\hline Almost everything we saw was unknown for me & 3.08 \\
\hline It seems very interesting that we are going to study things like we saw, during the next courses & 4.46 \\
\hline It was a funny and nice experience & 4.23 \\
\hline If I had known how this was going to be, I would not have gone to class & 4.69 \\
\hline This experience has made me more satisfied about being registered in Optics & 1.15 \\
\hline It was suitable experience for that day, but that is all & 4.00 \\
\hline It made me realize that Optics is much more than I thought & 1.82 \\
\hline I think it motivated me to study more & 3.62 \\
\hline I think now and then we should have activities to get us closer to what we will find in next years & 3.74 \\
\hline I think that, even though we are in 1st grade, we should have activities to get us closer to our & 4.64 \\
\hline working future now and then & 4.67 \\
\hline This experience has changed my perception about the possibilities of these studies & 3.36 \\
\hline I would have liked to enjoy this experience before I registered & 3.49 \\
\hline
\end{tabular}

Table V. Evaluation of the laboratory session about Optics received.

From Table IV and, with no intention of establishing cause-effect relations, it seems clear that the students who assisted voluntarily to the laboratory session have an intrinsic motivation remarkably superior to the ones who did not, towards the studies of Optics.

The data in Table $\mathrm{V}$ allow diverse readings, although if we focus exclusively on the scores then we observe how the experience was perceived as positive in a global way. Apart from the emotional response ("It was a funny and nice experience"), we notice that the most valued has to be regarding the orientation of the studies that they are running. Next we find the items related to a cognitive and affective change in the perception of Optics. The rest of the obtained scores in the items that undervalue the experience reinforce the usefulness that such experience was for the students. 


\subsection{Statistical analysis}

For this survey and sample of students some complimentary data was analyzed by means of the statistical pack SPSS (test for contrasting differences between averages) in order to find out the influence of some of the considered variables. We have to highlight that, due to the size of the sample, and to maintain a statistical meaning, the differences between the averages must be considerable.

\subsubsection{Sex}

There are statistically significant differences in the statement (Table XIII) "I could not register in what I wanted and this was my second choice” ( $\mathrm{p}=0.025)$ and quite substantial differences although not with that level of significance as (Table $\mathrm{V})$ : "I think now and then we should have activities to get us closer to what we will find in the next years" ( $p=0.089)$, in favor of women in both cases.

\subsubsection{Age}

Significant differences in (Table III): "I have completed the Spectacles module and I wanted to expand my studies" $(p=0.000)$; in this case, logically, in favor of the older students.

\subsubsection{Participation in the Experience}

We can appreciate a difference in relation to the statement in (Table IV): "I think I made the right choice when I registered in this Degree” ( $\mathrm{p}=0.090)$, in favor of the ones who participate in this experience.

If we combine more than one variable, the number of individuals decreases and, therefore, it turns out to be more difficult to acquire a statistical significance, nonetheless we highlight the following:

\subsubsection{Combination of sex, age and participation in the Experience}

(Table V) “Knowledge that I had about the contents" ( $\mathrm{p}=0.069)$.

From the former data (together with others that we have not included because of lack of statistical significance) it can be deduced that: students coming from Vocational Training (“took the spectacles module”) were older, knew less about the contents of the degree, but they are more motivated, they want to do the activities and they are happy about being registered, even though for them everything is much more difficult (they have enormous deficiencies in Mathematics and Physics). It seems as if the information that they receive in National Vocational Training is much less. Some students that came from High School would have preferred to have taken other studies and knew better what they were going to study. Women are more enthusiastic and participative than men.

\section{CONCLUSIONS}

1. When analyzing the possible influence of some variables of the sample who answered the survey, we detect profiles differentiated from the answers depending mainly on the previous studies, age and sex. These results should oblige us to attend the diversity and propose a differentiated treatment depending on their interests and previous knowledge looking "to hook" the students that think of Physics as an impassable wall.

2. The experience of taking students to the Optics laboratory and show them some situations and equipment which will show them a range of possibilities offered by their studies, as much regarding phenomena as with applications, it seems to show an alternative to reorienting vocationally the new students, especially if we take into account that a relevant number of them have not been registered due to altruistic and affective reasons. This allow us to connect to the searching of alternatives to the explained situation in this work, reinforcing the correlation between Universities and High Schools by means of different initiatives such as the ones realized by the Group of Divulgation of Optics from the University of Granada (Spain), which include the possibility of visits to the Optics laboratory, assistance in "El Parque de las Ciencias" with isolated initiatives or temporary expositions ${ }^{1-3}$. 
3. We should neither forget an ever-present problem among the students when they face subjects that are not directly related to the professional profile of their studies, in our case, "Physics for non-physicians", in which case they do not usually see them as important and they do not perceive it as essential subject. It does not help that there is an inherent Spanish tendency when the University teachings are reformed, and the degrees are getting ever-smaller, excluding other subjects (and departments) considered as “outsiders", and also the lack of knowledge of some lecturers who do not adapt the curricula of their subjects to the professional profile from other degrees (Physics for engineers, Physics for biologists, etc.)

\section{BIBLIOGRAPHY}

1. García, J.A., Romero, F.J., Perales, F.J. and García, R., "Visita al laboratorio de óptica: una experiencia motivadora para el alumnado de ESO y Bachillerato” Alambique 64, 109-120 (2010).

2. García, J.A., Huertas, R., Gómez-Robledo, L., Perales, F.J. and Romero, F.J., "Lo que el ojo no ve: análisis de una experiencia”, Rev. Eureka Enseñ. Divul. Cien. 7, 682-692 (2010).

3. García, J.A., Gómez-Robledo, L., Valero, E., Romero, F.J. and Perales, F.J., ¿Puede la divulgación científica ayudar a la labor docente universitaria?, Revista Española de Física, 26, 54-59 (2012). 